\title{
La Justicia Cotidiana en México. \\ Consideraciones a la Iniciativa Presidencial
}

Rubén Jaime Flores Medina*

Recibido: 11 junio 2016

\section{Resumen}

El tema de "Justicia Cotidiana"es una propuesta del gobierno federal para entender, prevenir y consecuentemente resolver, los problemas de convivencia que resultan entre los integrantes de nuestra sociedad; así como de aquellos que surgen de cada uno de sus miembros para con las autoridades locales o federales, con excepción de la materia penal. El propósito de este artículo es exponer y difundir a favor del amable lector, algunas consideracionesdesde la academia, y los contenidos de las diversas iniciativas presentadas por el gobierno federal en esa materia.

Palabras clave: Justicia. Justicia Cotidiana. Reforma Constitucional y legal.

\section{"The Daily Justice in Mexico. Considerations for the Presidential Initiative"}

\begin{abstract}
The concept: "Everyday Justice", is a proposal by the Federal Government to understand, prevent and consequently solve the problems of coexistence that are among the members of our society; as well as thosea rising from each of its members with local or federal authorities, except in criminal matters. The purpose of this article is to expose and spread the kind reader, some academic considerations, about the contents of the various initiatives by the federal government in this area.
\end{abstract}

Sumario: I. Introducción. II. El tema de Justicia. II.1 La Justicia cotidiana. III. La problemática actual. IV. La denominada "Justicia Cotidiana" y las iniciativas del Presidente de la República de México. IV.1 En materia regulatoria. IV.2 En materia de mecanismos de solución de controversias. IV.3 En materia de justicia cívica 
e itinerante. IV.4 En materia de registros civiles. IV.5 En materia del Código de Comercio. IV.6 En materia de Ley General de Salud. IV.7 En materia de resolución de fondo de conflictos. IV.8 En materia de Justicia Laboral. IV.9 En materia del Sistema Nacional de Impartición de Justicia. IV.10 En materia de trabajo. IV.11 En materia de propuesta de una ley general del ejecutivo, para la armonización y homologación de los registros públicos inmobiliarios y de personas morales y los catastros V. Algunas consideraciones. Bibliografía.

\section{Introducción}

El propósito del presente trabajo es difundiry analizar brevemente desde la academia, los contenidos jurídicos de las iniciativas de reforma a diversas materias, (exceptuando la penal) que han sido presentadas por el Presidente Enrique Peña Nieto. Lo anterior, por la importancia que representan dichas reformas constitucionales y legales -en una primera lectura-, para la pretendida resolución de las múltiples controversias que se suscitan día con día entre particulares y entre éstos y las autoridades locales y federales, de tan irresoluble solución en la práctica cotidiana.

En efecto, el pasado 28 de abril del presente año 2016, se firmó y envió finalmente al Congreso de la Unión por parte del Presidente de la República Enrique Peña Nieto, un paquete de reformas y adiciones constitucionales y legales; así como de nuevas leyes y decretos administrativos, que conformarán un nuevo Sistema Nacional de Impartición de Justicia, junto con mecanismos legales para lograr dar una solución a los problemas de convivencia y vecinales - entre otros- que puedan lograr en definitiva, la armonización de relaciones entre las personas, sus familias, dentro del trabajo y en la comunidad, asegurándoles un adecuado acceso a la justicia.

El tema a legislar surge del mensaje a la Nación que el primer mandatario expusiera el 27 de noviembre del 2014, dentro del cual expresó: “...pero la justicia no se agota -hay que decirlo-, en el ámbito penal...Hay una Justicia olvidada, la Justicia Cotidiana ... aquella que demanda la mujer, a quien le 
niegan el divorcio, el trabajador al que no le pagan su salario, o quien no puede cobrar una deuda...Esta justicia suele ser lenta, compleja y costosa, lo que provoca que la mayoría de los mexicanos no pueda acceder a ella con facilidad. A pesar de esta realidad, que es evidente, no se han presentado soluciones de fondo a estos problemas..." (Gobierno de la República, Discurso, 2014)

En ese sentido, el titular del ejecutivo federal encomendó, entonces al Centro de Investigación y Docencia Económicas (CIDE) del CONACYT, con participación fundamental del Instituto de Investigaciones jurídicas de la Universidad Nacional Autónoma de México (UNAM), a la organización de sendos foros de consulta con aquellos sectores de la sociedad civil, de la academia y los interesados sobre el tema, en el que resultara un informe de trabajo y las propuestas pertinentes que sirvieran de base para las actuales iniciativas legislativas.

Estas instancias se prestaron entonces, a la tarea de interpretar y precisar los contenidos de la materia en estudio, con el fin de integrar las opiniones sociales, académicas y técnicas al proyecto definitivo de reformas a las disposiciones legales y constitucionales que permitieran resolver la problemática de convivencia entre los diversos grupos sociales, ya fueren entre los mismos vecinos; dentro de las familias; para con patrones, médicos, prestadores de servicios o -finalmente- de cualquiera de los anteriores para con cualquier autoridad local o federal, siempre y cuando no sea de la materia penal.

El resultado se presenta en el conjunto de 13 iniciativas que contienen en resumen: Ocho reformas a diversos artículos de la vigente Constitución Política de los Estados Unidos Mexicanos, con propuestas de Ley. Tres iniciativas de reforma a leyes vigentes. La creación de una nueva Ley por el Ejecutivo de la Unión, así como un Decreto administrativo. Mismas que se comentan y discuten en el texto del presente trabajo. 


\section{El tema de Justicia.}

La palabra justicia es hoy en día un término multivoco por el uso que se le da en situaciones y contextos distintos. Se usa a conveniencia y eso lo demuestra la propuesta de iniciativa de reformas que el ejecutivo de la Unión nos presenta, a fin de resolver problemas diversos con esta denominada "Justicia Cotidiana".

Este concepto que amalgama e integra operativamente procedimientos jurisdiccionales, tanto como administrativos, se utiliza tratando de darle orientación a otros tipos de justicia como la recientemente aplicada "Justicia Alternativa"o a la más reciente "Justicia Restaurativa". Denominaciones que se han agregado a las tradicionales "Justicia distributiva, Justicia Conmutativa y a la Justicia Social" contempladas todas ellas por el Derecho Mexicano.

La Justicia como sabemos, es un concepto establecido a partir de enfoques y teorías, ya sea a través del pensamiento filosófico, del científico o del social. Ha sido considerada a través del tiempo, desde la idea de que es un "valor". Que es algo "valioso" por sí mismo.

Dicho concepto varía según se le ubique como algo "bueno" algo "útil" o "necesario".Es mediante el estudio de la justicia como elemento democrático, que le interesa a la comunidad y se establece u orienta como un "derecho a obtener justicia". Es con el concepto de justicia como elemento jurídico, cuando más se controvierte -sobre todo- por los que deben ser aplicadores o ejecutores de la misma.

La Real Academia Española de la Lengua nos dice que Justicia: Proviene del Latín Iustitia,(nom.) De Ius= (derecho, lo que proviene atendiendo al derecho) Es por eso que el sentido de la palabra nos lleva a entender a la justicia como: "...Darle a cada quien lo suyo conforme al derecho de nuestra ciudad..." parafraseando tanto a Ulpiano como Aristóteles; quienes basan su concepto en la aplicación primordial del derecho que rige a la comunidad en un momento determinado.

De esta manera podemos recordar que Ulpiano decía (apoyándose en 
la escuela de los Pitagóricos y de los Estóicos) que: "Iustitia est constans et perpetua voluntas ius suum cuique tribuendi; <Justicia es la constante y perpetua voluntad de dar (o concederle) a cada uno su derecho (que le corresponde) $>$. Donde reconoce a ésta, proveniente de la aplicación de lo bueno y de lo "justo".

Aristóteles por su parte, se inclina más por el concepto de "Justicia Conmutativa", al denominarle así: "Darle a cada uno lo que le corresponde, por ser suyo..." Lo que le corresponde está en proporción a lo que él contribuye con la sociedad, a sus méritos como persona o lo que requiere para satisfacer sus necesidades". ${ }^{2}$

Es con Justiniano que, en su Digesto (Corpus Iuris Civilis), comienza estableciendo al respecto de la Justicia, lo siguiente (D.1.1.1):

(...) ius a iustitia (...) ius est ars boni et aequi. “...El Derecho es justicia, el Derecho es el arte de lo bueno y lo equitativo..."

Más recientemente, John Rawls ${ }^{4}$, del que podemos deducir personalmente, basándonos en el llamado constructivismo jurídico estructurado por él, quela Justicia es resultado del acuerdo de voluntades de los miembros de una determinada comunidad, quienes la construyen para resolver situaciones, aunque tengan que "pactar" pérdidas o deméritos en sus derechos. Es ésta, entonces una forma de ver la justicia como algo derivado de los individuos, más que de la aplicación pura y dura de la ley.

Es desde mi punto de vista una variación al concepto etimológico de "Justicia como derivación misma de la declinación latina del concepto Derecho

\footnotetext{
${ }^{1}$ Al respecto consultar la Obra: "El Romano, la tierra, las armas. Evolución histórica de las Instituciones del Derecho Romano", Gavernet, Haroldo Ramón y Mojer, Mario Antonio, Editorial Lex, en rústica, La Plata, Argentina, 1992 (154 pp), Capítulo 2do.

${ }^{2}$ Ibídem.

${ }^{3}$ Confr. "Manual de Derecho romano. Historia e Instituciones", Arguello, Luis Rodolfo, Editorial Astrea, Buenos Aires, Argentina, 2000; De igual manera consultar:Gavernet, Haroldo Ramón y Mojer, Mario Antonio, Opus cit. pág. 38.

4 Rawls, John, "Teoría de la Justicia", Ed. Oxford, en español, 1999. Trata el tema constructivista de la justicia en toda su obra.
} 
(donde éste es genitivo: el Ius), por el cual se consagran las facultades o prerrogativas a ejercerse a través de la figura que nos ocupa: la Justicia (como dativo: Iustitia)".

\section{II.1 La Justicia Cotidiana}

Pero ¿Qué es la Justicia Cotidiana? Es el término que se acuña para indicar dos cosas principales: Que existe la necesidad de hacer efectiva la justicia formal en el campo de lo que es o se considera de la vida diaria o $<$ cotidiana $>$ para los individuos que pueblan en nuestro territorio (distinta de la justicia penal). Y por el otro; el lograr de una vez por todas que se integre un sistema de vida que haga efectiva o eficaz la convivencia en armonía de individuos, familias y ciudadanos en general; así como de éstos para con el Estado y sus autoridades.

La denominada como "Justicia Cotidiana" por el Presidente Peña Nieto, se entiende como aquél "...conjunto de instrumentos y mecanismos de que dispone o apoya el Estado para resolver directamente los conflictos de los ciudadanos con otros ciudadanos y. en algunos casos, de éstos con las autoridades públicas..." (CIDE, INFORME, 2015 p.7)

Es la justicia cotidiana, “...aquella distinta a la penal, que vivimos todos los días en nuestro trato diario y facilita la paz social y la convivencia armónica..." (Gobierno de la República, Discurso, 2016)

Es ésta, conforme lo dice el propio ejecutivo de la Unión dentro de la exposición de motivos de sus iniciativas; “...cuando se habla de justicia cotidiana, se hace referencia a ámbitos de justicia diferentes a la penal, pero igual de Importantes como: el civil, el laboral, el mercantil y el administrativo, entre otros, pues son los ámbitos más Importantes para vivir en comunidad..." (Gobierno de la República, Sistema de Información Legislativa de la Secretaría de Gobernación de la República Mexicana, 2016)

Es -según palabras de los investigadores del CIDE-, “...la consideración de la justicia cotidiana como servicio público...y comprende una doble dimensión del resultado de sus procedimientos (resoluciones y sentencias), 
como del trato que se otorga a los justiciables..." (CIDE, INFORME, 2015)

De esta manera, podemos decir que la justicia cotidiana -parafraseando al Presidente de la República- desde el enfoque técnico, se refiere...a las instituciones, procedimientos e instrumentos orientados a dar solución a los conflictos que genera la convivencia diaria en una sociedad democrática... implementados por el Gobierno Federal y debidamente armonizados por las entidades locales de gobierno.

Los conceptos de Justicia Cotidiana y el de Acceso a la Justicia ya se establecen en el vigente artículo 17 Constitucional, si analizamos detenidamente sus proposiciones en el tema como las siguientes:

“...Toda persona tiene derecho a que se le administre justicia por tribunales que estarán expeditos para impartirla en los plazos y términos que fijen las leyes, emitiendo sus resoluciones de manera pronta, completa e imparcial. Su servicio será gratuito, quedando, en consecuencia, prohibidas las costas judiciales..." (CPEUM, TEXTO VIGENTE, 2016)

Es obvio que se pueden señalar carencias e ineficiencias en su cumplimiento por parte de las autoridades obligadas a ello. Lo que justifica -en principiolas iniciativas en comento.

Estipula nuestra carta magna;

“...Las leyes preverán mecanismos alternativos de solución de controversias...”

No obstante la proposición constitucional, nos resulta necesario que se implemente una codificación nacional que armonice el desarrollo pleno de esta garantía.

Como disposición suprema que establece derechos, también consigna la obligación a cargo de los individuos que habitan y transitan por nuestro territorio, el de no hacerse justicia por su propia mano, dictando que:

${ }^{5}$ Confr. Constitución Política de los Estados Unidos Mexicanos, Artículo 17 párrafo Segundo. ${ }^{6}$ Confr. Constitución Política de los Estados Unidos Mexicanos, Artículo 17 párrafo Cuarto. 
“...Ninguna persona podrá hacerse justicia por sí misma, ni ejercer violencia para reclamar su derecho...",

Obligación que se deriva de la facultad originaria del Estado de hacer justicia. Esta disposición significa en los hechos, -y conforme a la doctrina política-, la existencia de un poder de facto para ejercer el "monopolio de Estado, en el uso de la fuerza pública; y estar en disposición de cumplir con su inobjetable función de regular el orden, la convivencia humana y la paz social,constituyéndose -de acuerdo a la doctrinaconstitucuionaluna especie de venganza pública, para dirimir controversias cuando hay particulares en conflicto.Diferente a aquél sistema donde los individuos eran los que ejercían autónomamente y sin la intervención de autoridad alguna, la llamada:"venganza privada".Situación aquella, que generabauna serie de conflictos mayores, por la natural anarquía que se producía con ello. Por lo cual, es el Estado, el que viene a constituirse como un supra-poder con la misión de ser imparcial y objetivo, en la solución de controversias entre particulares.

En merito a lo anteriormente repasado, podemos decir que el Estado Mexicano, aparte de regular la existencia de jueces y tribunales expeditos para procurar e impartir justicia; permanece con la obligación de establecer los medios, mecanismos y procedimientos que sean eficaces para evitar las acciones de particulares que afecten a otros particulares en detrimento de la convivencia cotidiana, la armonía social y el bienestar general de la población; y que no se agotan en la justicia penal.

\section{La problemática actual}

En México, en la actualidad se presenta la necesidad de hacer efectivos los derechos de "acceso a la Justicia" y el de justicia pronta, expedita, sin obstáculos, que restaure los derechos violentados por las autoridades o -en su caso- por otros particulares, de manera interpersonal. La única forma de hacerlo es presentando mecanismos eficaces por parte del Estado Mexicano, que hagan efectivos y viables dichos derechos constitucionales.

${ }^{7}$ Confr. Constitución Política de los Estados Unidos Mexicanos, Artículo 17 párrafo Primero. 
El mecanismo que más se ha privilegiado en el pasado es el de la heterocomposición; o sea, ante tribunales previamente establecidos donde se ejerza la autoridad inflexible del Estado.Dicho mecanismo -como se ha evidenciado a través del tiempo- ha sufrido un deterioro en la imagen y comprensión del justiciable por el tiempo y recursos que invierte en lograr solución a sus problemas.

Ha llegado la hora de que se validen los nuevos mecanismos -como los alternos- que ayuden a la autocomposición, sin que se haga justicia por propia mano, o se beneficien terceros de los conflictos, como lo vienen pretendiendo hacer ciertos grupos sociales o ciertos particulares, como aquellos en donde participan maestros disidentes en la educación básica y normal, en violación al artículo 17 constitucional.

La justicia lenta e ineficiente que se nutre de burocracia, ineficiencia y corrupción, es lógico que forme ciudadanos incrédulos en la administración e impartición de justicia, afectándose las familias, los negocios y la misma comunidad en su bienestar y progreso.

Sólo con un sistema de justicia que procese eficazmente las controversias que surgen diariamente en las comunidades se resolverán las diferencias entre los habitantes de nuestra nación y se pondrá una base segura para terminar con otras problemáticas que se avivan de la injusticia cotidiana.

Finalmente, podemos resumir como cuestiones tratadas en el Informe de resultados de los Foros de Justicia Cotidiana. Centro de Investigación y Docencia Económicas, de Abril de 2015, las que señalan como problemática a tratar, la resultante de 7 dimensiones de la justicia cotidiana:
A. La Justicia para los Trabajadores.
B. La Justicia para Ciudadanos.
C. La Justicia para Familias.
D. La Justicia para Emprendedores. 

E. La Justicia para Comunidades.
F. La Justicia en los Tribunales; y
G. La Justicia en las Escuelas.

\section{La denominada "Justicia Cotidiana" y las iniciativas del Presidente de la República de México}

Así, el mencionado paquete de reformas, adiciones y propuestas de nuevas Leyes que se analizan son 8 ocho en particular; pero que contienen 13 grandes modificaciones que se proponen -tanto a nuestra Constitución Política de los Estados Unidos Mexicanos, como a diversas leyes vigentesa fin de que integren un nuevo Sistema Nacional para la Impartición de Justicia. Propuestas que se pueden clasificar en cuatro grupos considerando la naturaleza jurídica de cada iniciativa, siendo estas:
A).- Las de reforma Constitucional con algunas propuestas de Ley (8);
B).- Las de reforma a leyes vigentes (3);
C).- La de creación de una nueva Ley por el Ejecutivo de la Unión; y
D).- La de un Decreto administrativo.

En ese tenor de ideas, las mencionadas iniciativas por la naturaleza de su contenido se describen a continuación.

Con la lectura simple de las iniciativas de ley propuestas por el ejecutivo, resaltan algunas cuestiones para ser discutidas y analizadas por los cambios que representan en el campo jurídico, más que político. Iniciativas que se pueden resumir en las siguientes:

\section{IV.1 En materia de mejora regulatoria}

El Gobierno Federal pretende con su iniciativa el implementar una política pública en materia de mejora regulatoria.

La Mejora regulatoria en efecto es, -según la Comisión Federal de Mejora 
Regulatoria- COFEMER:

“...Una política pública que consiste en la generación de normas claras, de trámites y servicios simplificados, así como de instituciones eficaces para su creación y aplicación, que se orienten a obtener el mayor valor posible de los recursos disponibles y del óptimo funcionamiento de las actividades comerciales, industriales, productivas, de servicios y de desarrollo humano de la sociedad en su conjunto.

...El propósito de la mejora regulatoria radica entonces en procurar los mayores beneficios para la sociedad con los menores costos posibles, mediante la formulación normativa de reglas e incentivos que estimulen la innovación, la confianza en la economía, la productividad, la eficiencia y la competitividad a favor del crecimiento, bienestar general y desarrollo humano..."8

Con esta iniciativa se pretende establecer: a) UnaLey General que establezca los principios y bases a los que deberán sujetarse los órdenes de gobierno, en el ámbito de sus respectivas competencias, en materia de mejora regulatoria; b) Un catálogo nacional de trámites y servicios federales, locales y municipales con el objetivo de generar seguridad jurídica a los particulares. c) La obligatoriedad para toda autoridad de cumplir con el catálogo referido.

Lo anterior nos permite adelantar la opinión de que se continúa con la tendencia centralizadora de poderes hacia el gobierno federal, en demérito de los estudios que sugieren el fortalecimiento de las entidades federativas para hacer efectivo un Federalismo Mexicano, donde se distribuyan las competencias en todos los campos; económicos, de gasto, de ingresos, políticos y sociales; entre otros.

\section{IV.2 En materia de Mecanismos Alternativos de Solución de Controversias}

En esta iniciativa el Ejecutivo Federal propone que el Congreso expida una Ley General partiendo de su respectiva reforma en la constitución, que establezca los principios y bases en materia de mecanismos alternativos de

${ }^{8}$ Consultar en el tema: COFEMER http://www.cofemer.gob.mx/contenido.aspx? contenido $=90$ 
solución de controversias, con excepción de la materia penal. En ese sentido, las leyes que se emitan por los Estados Federativos deberán ajustarse a la mencionada Ley General.

La razón de que se exceptúe la materia penal en esta iniciativa se debe a que se trata ya por separadodedicha cuestión, en el nuevo sistema penal acusatorio -adversarial y en conjunción con el Código Nacional de Procedimientos penales en vigor y con la vigente "Ley Nacional de Mecanismos Alternativos de Solución de Controversias en materia Penal", de fecha diciembre del 2014. ${ }^{9}$

De nuevo se advierte la necesidad desde el gobierno federal, de una homologación a nivel nacional de estos medios alternativos de solución de controversias, pero sólo en lo que respecta a ciertos mecanismos de solución de controversias domésticos o cotidianos; distintos a los ya regulados por la mencionada Ley Nacional de Mecanismos Alternativos de Solución de Controversias en materia Penal,a fin de lograr un adecuado control de los efectos de su aplicación en esta nueva área de solución de conflictos entre particulares y entre éstos y el Estado; desde el mismocentro de poderdel país.

\section{IV.3 En materia de justicia Cívica e Itinerante}

Como en las iniciativas anteriores, el titular del ejecutivo federal solicita que se expida una normatividad aplicable a los campos de la llamada justicia cívica y de la respectiva justicia itinerante, que establezcan los principios y bases a los que deberán sujetarse los órdenes de gobierno, en el ámbito de su respectiva competencia, en estas materias. Así como se realicen los cambios constitucionales pertinentes en el artículo $73^{\circ}$.

En su exposición de motivos refiere el ejecutivo que ya existen regulaciones en diversas entidades federativas a través de leyes o reglamentos de cultura cívica, para regular la convivencia entre particulares; no obstante, señala, esto no ha logrado permear en todo el país porque no existen criterios homogéneos que faciliten la convivencia diariade dichas personas y sus relaciones. La ignorancia resultante de la falta de socialización de las normas cívicas, -alega-

${ }^{9}$ Confr. http://www.diputados.gob.mx/LeyesBiblio/ref/lnmascmp.htm, consultada octubre 2016. 
y el desconocimiento de esas normas, en consecuencia, son un motivo por el que no se aplican.

Pero una educación cívica creo que deberá ser impulsada desde la sociedad misma, donde surtiría mayores efectos una regulación de esta magnitud, dada la doble "cara" del gobernado, que cumple con la norma cuando así le conviene, pero la incumple en tratándose de que se le inste a cumplirla en favor de sus vecinos o cercanos.

Por otra parte, la denominada Justicia itinerante debe conceptualizarse como aquella que debe impartirse atendiendo a la inexistencia o lejanía de las comunidades o poblados del lugar donde se imparte justicia por jueces o tribunales previamente establecidos, conforme lo mandata nuestra Carta Magna. Dicho concepto de justicia se asocia a la necesidad de contar con espacios físicos que le permitan al juez o resolutor de conflictos, el atenderlos y resolverlos eficientemente, de acuerdo a su competencia y jurisdicción.

Esta idea del juez itinerante se topa-creo yo- con un obstáculo; el de conflicto competencial y de jurisdicción. Veremos como el legislador federal atiende a partir de principios constitucionales y legales, esta circunstancia salvando los obstáculos que la práctica, la doctrina y la interpretación judicial le anteponen.

\section{IV.4 En materia de registros civiles}

El Ejecutivo de la Unión, considerando que toda persona tiene derecho a la identidad y a ser registrado de manera inmediata a su nacimiento, y que el Estado debe garantizar el cumplimiento de estos derechos; así como el deber de toda autoridad competente en esta materia la obligación de otorgar, de manera gratuita, la primera copia certificada del acta de registro de nacimiento, es que impulsa esta iniciativa de reforma constitucional, a efecto de que se expida por el legislador federal, una ley general que venga a homologar y armonizar la organización y el funcionamiento de los registros civiles, los registros públicos inmobiliarios y de personas morales de las entidades federativas, así como de los catastros municipales.

Lo anterior debido a la evolución y dinámica que la sociedad ha revelado a 
la autoridad al exigirle el reconocimiento de diversidades y conveniencias de sectores que antes no se habían manifestado.

Por ello, con el propósito de incorporar a estos sectores y garantizar a toda la población certeza y seguridad jurídicas, es por eso que nos anuncia estas medidas de efecto nacional y de evidente coordinación local. Lo que esperamos de las normas reglamentarias en esta materia, es que se otorgue a la familia el lugar que le corresponde, privilegiando los derechos de sus integrantes por sobre las preferencias que pudiesen tener algunos sectores y su implicación dentro de las instituciones civiles como el matrimonio, la adopción y el parentesco.

Además se otorgue seguridad y certeza jurídica a las personas morales en su devenir comercial y de negocios; así como a la tenencia de la tierra.

\section{IV.5 En materia del Código de Comercio}

El Titular del Poder Ejecutivo Federal, emite una iniciativa con proyecto de decreto por el que se reforman y adicionan diversas disposiciones del Código de Comercio, como las siguientes:

Se REFORMAN los artículos 1076, párrafo segundo y las fracciones III y IV; 1079, fracción IV; 1123, párrafo tercero; 1331; 1333; 1350; 1390 Bis, párrafo primero; 1390 Bis 6 ; 1390 Bis 7, segundo párrafo; 1390 Bis 9, primer párrafo; 1390 Bis 10; 1390 Bis 24, primer párrafo; 1390 Bis 25; 1390 Bis 29, segundo párrafo: 1390 Bis 33; 1390 Bis 36; 1390 Bis 37, cuarto párrafo; 1390 Bis 38, tercer párrafo; 1390 Bis 39; 1390 Bis 40, primero, segundo y tercer párrafos; 1390 Bis 41, en sus fracciones I, II y III; 1390 Bis 42, primer párrafo; 1390 Bis 45, segundo párrafo; 1390 Bis 46; 1390 Bis 47, primer y tercer párrafos; 1390 Bis 48; 1401, tercer párrafo; 1406, y 1407, y se ADICIONAN un artículo 1068 Bis; un segundo y tercer párrafos al artículo 1390 Bis 1; un segundo párrafo, recorriéndose en su orden los subsecuentes, al artículo 1390 Bis 18; un segundo párrafo al artículo 1390 Bis 20; un último párrafo al artículo 1390 Bis 37 ; los párrafos tercero, cuarto y quinto al artículo 1390 Bis 45, todos del Código de Comercio. 
De estas propuestas se advierte un gran cambio, propiciar reformas y adiciones al Código de Comercio, a fin de dar viabilidad a los denominados Juicios Orales en la materia mercantil y se privilegie su uso para hacer de esta una justicia expedita. Adecuaciones reclamadas desde la firma del Tratado de Libre Comercio con Estados Unidos de América y Canadá por parte de México.

Resaltan dos cuestiones de procedimiento, se prevé que las pruebas en el juicio ejecutivo mercantil abandone la disposición que establecía en el art. 1401 que éstas deberían prepararse al modo del Código Federal de Procedimientos Civiles, para fijar la obligación de que se preparen y desahoguen de acuerdo al propio Código de Comercio. Y la otra que se agilizarán los juicios orales mercantiles al permitir que se lleven a cabo en cualquier asunto independientemente de la cuantía. Pero fija tres años para ello. A partir de su vigencia, se podrán interponer en litigios hasta por un millón de pesos y aumentará en quinientos mil cada año, hasta el tercero en los que no se fijará límite alguno.

\section{IV.6 En materia de Ley General de Salud}

El Presidente de la República envió -igualmente que las anteriores- una iniciativa con proyecto de decreto por el que se reforman y adicionan diversas disposiciones de la Ley General de Salud, a como las siguientes:

Se REFORMAN los artículos 3o, fracción I; 17 bis; 17 bis $1 ; 17$ bis 2;18, párrafo segundo; 27, fracciones X y XI; 339, párrafo quinto; 340, y se ADICIONAN los artículos 3o., con una fracción Mi bis; 13, apartado A, con una fracción VIII bis, y el apartado $\mathrm{B}$, con una fracción II bis; 17 bis 3; 17 bis $4 ; 17$ bis 5 ; 17 bis $6 ; 17$ bis 7; 27, con la fracción XII; 51 bis 3, con un segundo párrafo; 400, con un tercer y cuarto párrafo; 414 Ter; 420, con un párrafo segundo, y 421 Quáter, de la Ley General de Salud.

Esta iniciativa pretende regular situaciones de emergencia sanitaria nacional; regular un modelo de gestión de los servicios de salud; impulsar los Medios Alternos de Solución de Controversias en la materia de salud y fortalecer a la Comisión Nacional de Arbitraje Médico al efecto; y crear la 
Comisión Federal para la Regulación y Vigilancia de los Establecimientos y Servicios de Atención Médica, como órgano desconcentrado que fije las políticas en materia de salud.

Como siempre, hasta que no se fijen regulaciones que pongan límites a los comerciantes y traficantes de medicamentos para la salud, poco se podrá hacer en esta materia.

\section{IV.7 En materia de resolución de fondo de conflictos}

La materia que contiene esta iniciativa es vital para el cometido de la presidencia de la República en materia de Justicia Cotidiana, pues subyace entre la población el problema de la inadecuada resolución de conflictos en todos los ámbitos, pero primordialmente en los que surgen entre particulares todos los días; y que al decir de las autoridades constituye -fuera de las cuestiones penales- el $90 \%$ de los conflictos a resolver.

Pero igualmente, es una materia sensible, ya que pone al juez o al tribunal, ante disyuntivas irresolubles, considerando que la ley es de estricta aplicación y los procedimientos reglados. Ahora se pretende dejar al juzgador en la posición de considerar si obvia -por decirlo de alguna manera- la técnica procesal privilegiando la solución de fondo de la controversia que se le plantea. Esa es la naturaleza misma de la iniciativa presidencial: privilegiar la justicia por sobre la aplicación irrestricta del procedimiento: o sea la técnica procesal misma.

Por su contenido, se trata de reformar el párrafo primero del artículo 16 y de adicionar un tercer párrafo, recorriéndose en su orden los subsecuentes al artículo 17, ambos de la Constitución Política de los Estados Unidos Mexicanos, para quedar como sigue:

Artículo 16.

"Nadie puede ser molestado en su persona, familia, domicilio, papeles o posesiones, sino en virtud de mandamiento escrito de la autoridad competente, que funde y motive la causa legal del procedimiento. En los juicios y procedimientos seguidos en forma de juicio en los que se establezca como regla 
la oralidad bastará con que quede constancia de ellos en cualquier medio que dé certeza de su contenido y del cumplimiento de lo previsto en este párrafo.

Artículo 17.

..."siempre que no se afecte la igualdad entre las partes, el debido proceso u otros derechos en los juicios o procedimientos seguidos en forma de juicio, las autoridades deberán privilegiar la solución del conflicto sobre los formalismos procedimentales. " 10

\section{IV.8 En materia de Justicia laboral}

En síntesis, se REFORMAN el inciso a) en sus párrafos primero, tercero y cuarto de la fracción III y el inciso d) de la fracción $\mathrm{V}$ del artículo 107; las fracciones XVIII, XIX, XX, XXI, el inciso b) de la fracción XXVII; y se ADICIONAN la fracción XXII bis y el inciso c) de la fracción XXXI del apartado A del segundo párrafo del artículo 123, todos de la Constitución Política de los Estados Unidos Mexicanos.

El contenido de la reforma establece los juzgados o tribunales del trabajo de esencia judicial. Con autonomía del Ejecutivo lo que llevará a otro nivel los derechos del trabajo tutelados en la Constitución. Igualmente se establece la competencia federal para el registro y conocimiento de los contratos colectivos y del denominado Contrato-Ley, a fin de adecuar y armonizar este tema desde el gobierno federal. En consecuencia se fija un organismo descentralizado de la administración pública federal para que se haga cargo de esta función.

\section{IV.9 En materia del Sistema Nacional de Impartición de Justicia}

Si se pudiese jerarquizar de alguna manera la lista de iniciativas, esta sería la más importante porque previene un sistema nacional de coordinación entre la Federación y las entidades locales para establecer modelos de política pública, de apoyo, colaboración y coordinación en la materia judicial y de

${ }^{10}$ Texto de la mencionada iniciativa por dictaminarse en la respectiva comisión del Congreso de la Unión. 
impartición general de la justicia.

Dicha iniciativa en lo particular contiene la reforma a los artículos 116, fracción III y 122 fracción IV, y se adiciona un párrafo noveno al artículo 17 y una fracción XXIX-X al artículo 73 de la Constitución Política de los Estados Unidos Mexicanos.

En síntesis, previene la expedición de una ley general que posibilite dicha coordinación y que establezca los mecanismos para hacerla efectiva. Además estipula la manera de conformase los órganos administradores dentro de los poderes judiciales: el Consejo de la Judicatura, su organización e integración.

\section{IV.10 En materia de trabajo}

Consecuente con la reforma constitucional, se proponen reformas y adiciones a la ley federal del trabajo a fin de construir un modelo de justicia laboral. Estas son en lo particular: Reforma a los artículos 390, 895 fracciones III y IV y 931, y se adicionan los artículos 390 Bis, 390 Ter, 931 Bis y 931 Ter de la Ley Federal del Trabajo.

\section{IV.11 En materia de propuesta de una ley general del ejecutivo, para la armonización y homologación de los registros públicos inmobiliarios y de personas morales y los catastros}

Por último, se debe destacar la propuesta del Presidente de la República para que se expida una ley general que integre el propósito de armonización general de los registros públicos, pero en la materia inmobiliaria, catastral y de comercio.

Esto facilitará, junto con la homologación de los registros civiles un total control de las actividades de publicitación registral.

\section{Algunas consideraciones}

Primero.- La problemática planteada en el presente trabajo surge del punto de vista de las dimensiones de los conflictos personales, interpersonales y de autoridad que se pretenden resolver con las medidas y propuestas de 
mecanismos que el Ejecutivo de la Unión, presenta, para darle eficacia al tema de justicia -exceptuando la penal- en base a lo mandatado en los artículos 16 y 17 constitucionales.

Para ello, convoca a los Tribunales locales y al Federal, a que conformen un Sistema Nacional de Impartición de Justicia en donde se haga eficiente la colaboración, coordinación y cooperación entre tribunales a fin de acercar la justicia a todos los individuos en la República. Y a los juzgadores en general, a que privilegien la solución del fondo de los conflictos por sobre la formalidades de los procedimientos; ya que hasta ahora, se cumple con las leyes procesales aunque esto implica que se postergue la solución al fondo de las controversias en perjuicio del justiciable que ve violentados con ello, sus derechos, su patrimonio y su tiempo, por decir lo menos.

La innovación consiste entonces, en "flexibilizar" la aplicación de los procedimientos -dentro de lo que marcan las leyes- para que el juzgador o autoridad que resuelva conflictos, lo haga privilegiando la solución del fondo de la controversia y no permita que la técnica procesal se sobreponga a los fines de hacer justicia: que son -entre otros- el solucionar problemas comunitarios, ya sea de trabajo, escolares o de familiar, en beneficio de la armonía, el orden público y la paz social.

Dicha innovación mediante la llamada "Justicia Cotidiana", se entiende como una variación que permite la delimitación de ocho dimensiones del problema de acceso a una justicia al alcance de todos. Esas dimensiones son en materia laboral, en materia de solución a problemas interpersonales de los individuos, en materia familiar, en materia de justicia para emprendedores, en materia de justicia para las comunidades, en la mencionada justicia dentro de los tribunales y la justicia en las escuelas.

Segundo.- Las iniciativas presentadas al legislador por el Presidente de la República, en su conjunto son adecuadas al contexto técnico jurídico que prevalece. Pero tienen el propósito general de privilegiar las facultades y competencias del gobierno federal, favoreciendo una tendencia a centralizar dichas potestades, en detrimento de las propias de las entidades estatales y 
municipales, quienes deberían seguir ejerciendo autónomamente -al menosde la toma de ciertas decisiones, en el marco de un auténtico federalismo; y garantizar de esa forma a sus habitantes -a quienes conoce mejor que la federación-, de un cierto grado de seguridad jurídica y de acercar a su población mecanismos de justicia.

Un ejemplo de la tendencia a centralizar la toma de decisiones y el control de los trámites y procedimientos, lo constituye la iniciativa que privilegia a la Secretaría de Desarrollo Agrario, Territorial y Urbano (SEDATU) en la tarea de la organización de la llamada interoperabilidad de la "Plataforma Nacional de Información Registral y Catastral" que la iniciativa propone. Así como podrá también operar con el Registro Nacional Agrario.

Tercero.- La iniciativa de Reformas al Art. $17^{\circ}$ Constitucional, en cuanto a la garantía del Debido Proceso, nos lleva a considerar que introduce un cambio en la cultura jurídica del país, al priorizar el tema de "Justicia" por el concepto imperante de "legalidad".

Pero también es cierto que el viejo dilema de las autoridades ejecutoras o que son intérpretes de las leyes, quienes deben cumplir estrictamente con éstas; y no pueden apartarse del texto de la norma (haciendo cierto el dilema: de que la ley es dura pero es la ley...), no obstante no se haga justicia en el caso concreto; seguirá cumpliéndose por jueces y autoridades, so pena de desacato a la ley, en perjuicio -insisto- del justiciable.

Es claro que se intenta un cambio de paradigma para los jueces y justiciables, pero me temo que esta reforma constitucional es insuficiente aún, para modificar los viejos hábitos del juzgador de sujetarse en extremo, a las formas procedimentales o procesales; victimizando con ello al justiciable, quien deberá seguir tolerando que las formas procedimentales y sus técnicas predominen, por sobre la necesidad del gobernado de que se otorgue a cada quien lo que le corresponde; y no lo que surja de la aplicación despiadada y sin consideración de la norma jurídica aplicable al caso.

Lo anterior es así porque no se introduce en las iniciativas de reforma al 
mencionado artículo 17, y de una vez por todas, el principio constitucional -tal y como ya lo hacen otras constituciones latinoamericanas- que establezca la obligación a los jueces y tribunales al resolver conflictos o controversias a través de nuestras leyes que, en caso de duda sobre la aplicación estricta de una ley o hacer "justicia" en un caso concreto, prevalezca el criterio del juzgador en otorgar "justicia amplia" a favor de las partes en conflicto, resolviendo así el trámite o proceso, con sentido común o arbitrio, que deje satisfecha a dichas partes, sin menoscabo -desde luego- de la propia ley aplicable a la controversia; pero que sin desacatarla en el fondo -aunque pueda hacerse en la forma-, se propicie por el juez, un encuentro de intereses entre las partes.

Digo que quedó insuficiente dicha reforma, porque no se atrevió el Ejecutivo, a establecer una reforma integral que establezca como Principio Constitucional, el predominio de los valores implícitos en el caso concreto, por sobre las formas aplicables por la ley, a cada controversia en cuestión. Y como establecen algunas normas del derecho comparado, en ese caso: "No deberá sacrificarse a la Justicia por la sola omisión de formalidades por alguna de las partes..." Pero en ese caso quedaría una cuestión por dirimir: Si le mandata al juzgador, pero no le ofrece un marco constitucional para que pueda discriminar los casos en los que no podrá utilizar el arbitrio, frente a la norma reglada, impidiendo resoluciones por capricho o en contra del sentido común.

Arguello, Luis Rodolfo,"Manual de Derecho romano. Historia e Instituciones",Editorial Astrea, Buenos Aires, Argentina, 2000 Constitución Política de los Estados Unidos Mexicanos. Consultada 5/05/2016: http://www.diputados.gob.mx/ LeyesBiblio/pdf/1_29ene16.pdf

Consulta al Diario: Talla Política. http://www.tallapolitica.com. $m x / ? p=493314$

Discurso del 27 de Noviembre del 2014, con motivo de la desaparición de los 43 normalistas de Ayotzinapa, en Iguala Gro. $\mathrm{Y}$ en el que se anuncia el establecimiento de políticas públicas 


\section{Bibliografía}

junto con medidas para lograr un México en Paz y con seguridad. Consultada el día 5 de mayo del 2016 a las 20.00 hrs. Consultado el documento en:

http://www.gob.mx/presidencia/videos/mensaje-a-la-nacionpor-un-mexico-en-paz-con-justicia-unidad-y-desarrollo

Discurso del 28 de Abril del 2016, con motivo de la firma del paquete de iniciativas que serían turnadas y entregadas al Congreso de la Unión; además de reconocimientos a los participantes en las tareas de Diálogo sobre el tema de Justicia Cotidiana. http://www.gob.mx/presidencia/discursos

Flores Medina, Rubén Jaime, "Federalismo Judicial Cooperativo", Revista Jurídica Jalisciense, No. 1, 2da. Época, Universidad de Guadalajara, 2010.

Gavernet, Haroldo Ramón y Mojer, Mario Antonio, "El Romano, la tierra, las armas. Evolución histórica de las Instituciones del Derecho Romano",EditorialLex, en rústica, La Plata, Argentina, 1992

Gobierno de la República Mexicana; Informe CIDE:https://www. gob.mx/justiciacotidiana,

Página consultada 30 abril del 2016, 20.00 horas.

Informe de resultados de los Foros de Justicia Cotidiana. Centro de Investigación y Docencia Económicas, CIDE, Abril de 2015. Documento_JusticiaCotidiana_pdf

Rawls, John, "A Theory of Justice" Ed. Oxford,edición en español,1999.

Sistema de Información Legislativa de la Secretaría de Gobernación de la República Mexicana. Consultas en; http:// www.gobernacion.gob.mx/; y http://sil.gobernacion.gob. $m x /$ Reportes/GeneracionReportes/reporteAutomaticol. php? TipoReporte $=1 \&$ Periodo $=3$ 